\title{
Plasticity in Brain Sexuality Is Revealed by the Rapid Actions of Steroid Hormones
}

\author{
Luke Remage-Healey and Andrew H. Bass \\ Department of Neurobiology and Behavior, Cornell University, Ithaca, New York 14853
}

Divergent steroid hormone profiles can shape the development of male versus female neural phenotypes, but whether they also determine differences in the short-term, neurophysiological patterning of behavior is unknown. We now show that steroid hormone-specific modulation of a vocal pattern generator (VPG) diverges between reproductive morphs in a teleost fish. Only type I male midshipman acoustically court females, whereas type II males steal fertilizations from type I males and, like females, generate only agonistic calls. The androgen 11-ketotestosterone (11kT), but not testosterone (T), rapidly (within $5 \mathrm{~min}$ ) increases type I VPG output. As now shown, T, but not $11 \mathrm{kT}$, rapidly increases VPG output in type II males and females, consistent with the predominant circulating androgen in type II males and females $(\mathrm{T})$ versus type Is $(11 \mathrm{kT})$. Receptor and enzyme antagonists reveal an unexpected divergence in androgen- versus estrogen-dependent mechanisms in, respectively, type II males versus females. Cortisol, the main circulating glucocorticoid, also has divergent actions: suppressing versus increasing VPG output in, respectively, type II males and females versus type Is. In summary, rapid steroid action on VPG activity is uncoupled from gonadal phenotype (convergent between type II males and females), whereas the receptor-mediated mechanisms of androgen action are predicted by gonadal phenotype (both male morphs are sensitive to androgen receptor blockade, whereas females are not). A comparable mix of neuroendocrine traits may explain the widespread distribution of intrasexual behavioral phenotypes among teleosts and vertebrates in general. Moreover, the fundamental organization/activation principles that predict the steroid-dependent expression of "maleness" and "femaleness" may now include rapid steroid actions on the neurophysiological patterning of behavior.

Key words: nongenomic; extranuclear; membrane; neuromodulation; central pattern generator; estrogen

\section{Introduction}

Neuroendocrine mechanisms are proposed to underlie variation in behavioral phenotypes, including human personality types and sexual preferences (de Vries and McCarthy, 2006). An opportunity to examine discrete rather than continuous variation in such mechanisms is provided by animals that exhibit alternative reproductive tactics (ARTs) (Rhen and Crews, 2002; Knapp, 2003). Teleost fishes, which comprise nearly half of all living vertebrates (Nelson, 1994), present many examples of male ARTs (Mank and Avise, 2006). Typically, territorial males exhibit traits adapted to nest and egg defense (e.g., large body size) and mate attraction (e.g., hypertrophied neural circuitry for advertisement calling). In contrast, noncourting "sneaker" males steal fertilizations from territorial males, achieved in part by mimicking female behavior, and exhibit a combination of traits typical of

\footnotetext{
Received Sept. 30, 2006; revised Nov. 29, 2006; accepted Dec. 19, 2006.

This work was supported by a National Science Foundation (NSF) predoctoral fellowship, a National Institute of Mental Health training fellowship, NSF Doctoral Dissertation Improvement Grant IBN-0407802 (L.R.-H.), and NSF Grants IBN-9987341 and IOB-0516748 (A.H.B.). We thank David McCobb for mifepristone, Sarah London for advice on fadrozole dose and time course considerations, Novartis for generously providing fadrozole, and Elizabeth Adkins-Regan, Paul Forlano, Matthew Grober, Jonathan Lee, Barney Schlinger, and two anonymous reviewers for discussion and/or comments on this manuscript.

Correspondence should be addressed to Luke Remage-Healey, Laboratory of Neuroendocrinology and Brain Research Institute, University of California, Los Angeles, 621 Charles Young Drive South, P.0. Box 951606, Los Angeles, CA 90095-1606. E-mail: healey@ucla.edu.

DOI:10.1523/JNEUROSCI.4282-06.2007

Copyright $\odot 2007$ Society for Neuroscience $\quad$ 0270-6474/07/271114-09\$15.00/0
}

males (e.g., sperm production) and females (e.g., nonhypertrophied calling circuitry) (Bass, 1996; Oliveira et al., 2005).

An intraspecific divergence in circulating steroid hormone levels occurs in vertebrates with ARTs (Rhen and Crews, 2002), although the neural consequences of such differences are unclear. In teleosts, circulating levels of the androgen 11-ketotestosterone $(11 \mathrm{kT})$ [non-aromatizable derivative of testosterone like $5-\alpha$ dihydrotestosterone (DHT)] is often several fold higher in territorial males (Brantley et al., 1993; Oliveira, 2004). In sneakers, long-term $11 \mathrm{kT}$ treatment can induce hypertrophied morphological traits that partially mimic those of territorials, yet $11 \mathrm{kT}$ does not activate territorial behavior and can intensify sneaking (Lee and Bass, 2005; Oliveira et al., 2005). This discrepancy suggests that each morph has unique steroid-dependent mechanisms that modulate the neural patterning of reproductive behavior, yet neurophysiological evidence for such mechanisms has not been forthcoming.

The midshipman fish provides a model for the direct translation of neural activity into context-dependent vocal behavior. The rhythmic firing properties of a vocal pattern generator (VPG) directly establish the temporal properties of natural calls (Bass and Baker, 1990). Territorial, nesting type I males acoustically court females with advertisement "hums," whereas type II males neither build nests nor hum but rather steal fertilizations from type I males (all adults emit agonistic "grunts") (Brantley and Bass, 1994). The dominant circulating androgen is $11 \mathrm{kT}$ in 
A

\section{Vocal control pathway}

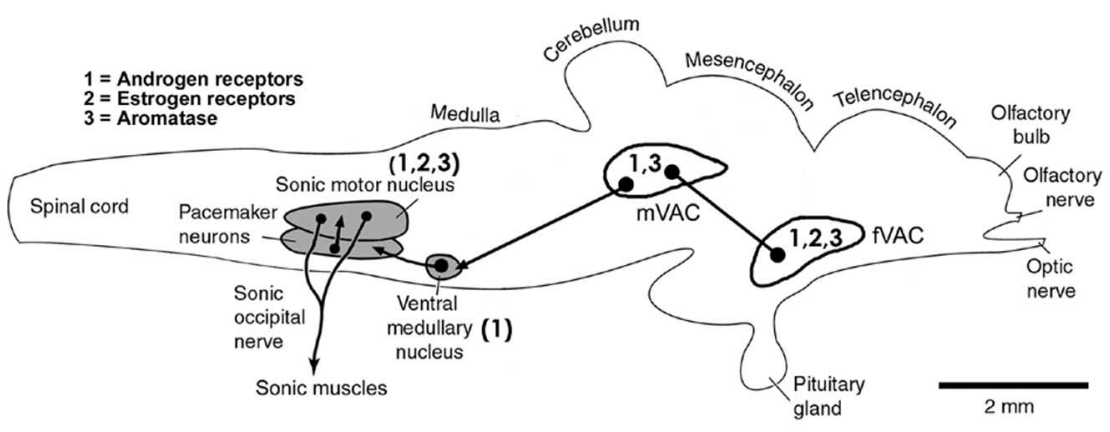

B

Fictive call - baseline
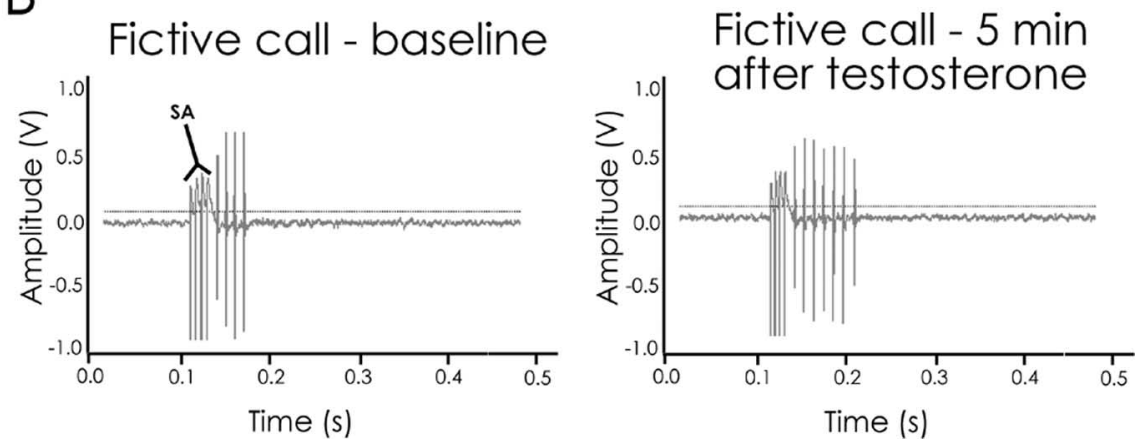

Figure 1. A, Vocal control pathway of midshipman fish (adopted from Goodson and Bass, 2002). Sagittal view of the brain showing pattern of connectivity of forebrain (f) and midbrain $(m)$ vocal acoustic centers $(V A C)$ and a hindbrain-spinal VPG (shaded region), which determines the temporal properties of natural vocalizations. The VPG includes (1) paired midline sonic motor nuclei that innervate the sonic muscles via occipital nerve roots, (2) adjacent columns of pacemaker neurons that directly establish the firing rate of the motor neurons, and (3) ventral medullary nuclei that bilaterally couple the motor neuron-pacemaker circuit and link it to the mVAC and fVAC (Bass and Baker, 1990) (also see Goodson and Bass, 2002; Kittelberger et al., 2006). The expression patterns of androgen receptors, estrogen receptors, and aromatase in the vocal control pathway of all three adult morphs are as indicated by numbers (data from Forlano and Bass, 2005; Forlano et al., 2005a,b). B, 0scillograms of fictive calls evoked by mVAC stimulation from a type II male; stimulus artifact $(S A)$ is indicated. Each fictive call consists of a series of compound action potentials (rhythmic VPG activity) that predicts the fundamental frequency and duration of natural calls (see Materials and Methods). At left is a fictive call recording taken at baseline, before hormone treatment. At right is a recording taken $5 \mathrm{~min}$ after intramuscular injection of testosterone.

type I males, whereas it is testosterone (T) in type II males and females (Brantley et al., 1993; Knapp et al., 1999; Sisneros et al., 2004). Females have up to 20 -fold higher concentrations of $17-$ $\beta$-estradiol (E2) than either male morph.

Although steroids such as T and E2 can shape sex differences in neural function and behavior via long-term (days to weeks) mechanisms (for review, see Arnold and Breedlove, 1985), it remains unknown whether divergent circulating steroid profiles have consequences for the rapid neurophysiological patterning of behavior in any vertebrate. Taking advantage of recent findings that steroids modulate VPG activity within minutes in type I midshipman (Remage-Healey and Bass, 2004), we show that rapid androgen actions on VPG output are predicted by the predominant circulating androgen in type II males and females (T) versus type I males $(11 \mathrm{kT})$. Receptor and enzyme antagonists then reveal predominantly androgen- versus estrogen-dependent mechanisms in, respectively, type II and I males versus females. Surprisingly, cortisol, the principle glucocorticoid, suppresses VPG output in type II males and females but facilitates it in type I males. Comparable, divergent neuroendocrine mechanisms may explain intrasexual behavioral variation in other vertebrates (Rhen and Crews 2002; Roselli et al., 2004), including that asso- ciated with divergent endocrine profiles in primates (Maggioncalda et al., 2002; Morris et al., 2004).

\section{Materials and Methods}

Subjects. Females $(11.4-17.1 \mathrm{~cm})$ and type II males $(9.3-11.2 \mathrm{~cm})$ were collected from either offshore trawls or nest sites in northern California during summer and fall of 2003-2005 (Sisneros et al., 2004). Type I males (12.4-19.2 $\mathrm{cm})$, collected under similar conditions, were used in a subset of experiments. Fish were maintained in artificial seawater tanks at 15$16^{\circ} \mathrm{C}$ on a diet of goldfish for no more than $35 \mathrm{~d}$ until experimentation.

Neurophysiology. All procedures, including surgery and extracellular recordings, were conducted in vivo and followed those presented previously (Bass and Baker, 1990; Goodson and Bass, 2000; Remage-Healey and Bass, 2004). The brain and rostral spinal cord were exposed by dorsal craniotomy under general anesthesia (0.025\% benzocaine; Sigma, St. Louis, MO) and long-lasting local anesthesia [surgical-site subdermal injection of $0.25 \%$ bupivicaine (Abbott Laboratories, Chicago, IL) with 0.01 $\mathrm{mg} / \mathrm{ml}$ epinephrine (International Medication Systems, El Monte, CA)]. After surgery, fish were stabilized in a Plexiglas tank and perfused through the mouth with fresh saltwater maintained at $16-17^{\circ} \mathrm{C}$ with a peltier device. During in vivo recording, exposed brain areas were covered with Flouroinert (3M, St. Paul, MN), and intramuscular injections of pancuronium bromide were used for immobilization $(0.5 \mathrm{mg} / \mathrm{kg}$; Astra Pharmaceutical Products, Westborough, MA). All experimental procedures were approved by the Cornell University Institutional Animal Care and Use Committee.

Fictive calls that reflect the rhythmic activity of a hindbrain-spinal VPG were evoked by brief (25-30 ms) trains of stimuli (0.1 ms duration, $300 \mathrm{~Hz})$ delivered to midbrain sites through insulated tungsten electrodes $(125 \mu \mathrm{m}$ diameter; $5 \mu \mathrm{m}$ exposed tips; A-M Systems, Calsborg, WA). The midbrain site used here and previously (Bass and Baker, 1990; Remage-Healey and Bass, 2004) projects directly to the VPG (Fig. 1 A) (Goodson and Bass, 2002; Kittelberger et al., 2006). Fictive calls were recorded with an extracellular electrode (Teflon-coated silver wire with exposed ball tip 50-100 $\mu \mathrm{m}$ in diameter) placed on a ventral occipital nerve root that innervates the ipsilateral sonic muscle (Fig. $1 A, B$ ).

Each fictive call recorded from an occipital nerve root consisted of a burst of compound action potentials, with each spike-like potential representing the synchronous activity of the ipsilateral sonic motor neurons; both nerves fire in-phase (Fig. 1B) (Bass and Baker, 1990). Recordings consisted of 15 fictive call responses to 15 trains of stimuli at $1 \mathrm{~s}$ intervals and were digitized using a Power Macintosh 8100 (Apple Computers, Cupertino, CA) with IGOR Pro software (WaveMetrics, Lake Oswego, OR). The total duration of each fictive call that is predictive of the duration of natural calls (Bass and Baker, 1990) was measured in all experiments (Fig. $1 B$ ). The fictive call discharge frequency (number of fictive pulses per burst duration), which is predictive of the fundamental frequency of natural calls (Bass and Baker, 1990), and burst latency, measured as the time interval between stimulus end and burst onset, were also measured for the four main steroid treatment groups (T, 11kT, E2, and cortisol).

For hormone delivery, a 23 gauge butterfly needle (infusion set SV23BLK; Terumo, Tokyo, Japan) attached to a $1 \mathrm{cc}$ syringe prefilled 
with hormone or drug solution (doses outlined below) was inserted into the dorsal epaxial muscle before the start of recordings. For experiments when a receptor antagonist or enzyme inhibitor was delivered before a hormone (see below), one butterfly/syringe each (antagonist/inhibitor, hormone) was inserted into the left and right dorsal epaxial muscles. For each experiment, two baseline recordings were obtained (separated by a 5 min interval) before hormone treatment. These baseline recordings were used to standardize all subsequent recordings for that experiment (relative to baseline output $=100 \%$ ). For all experiments described below, records were subsequently taken at 5, 15, 30, 45, 60, 90, and $120 \mathrm{~min}$ after steroid injection.

Rapid steroid hormone effects. We studied the influence of the naturally occurring androgenic and estrogenic steroids T, 11kT, and E2 (see Introduction) on vocal patterning in type II males and females. Cortisol, the primary glucocorticoid in midshipman (Sisneros et al., 2004), was also studied for two main reasons. First, field studies of the closely related toadfish (Opsanus beta) show fourfold increases in cortisol levels during the shift from a non-calling to a calling state (Remage-Healey and Bass, 2005). Second, previous studies of type I male midshipman and toadfish identify a rapid cortisol effect on fictive call duration (Remage-Healey and Bass, 2004, 2006).

Only one steroid was delivered per experiment at doses based on the same method used previously (Remage-Healey and Bass, 2004, 2006) to achieve rapid changes in circulating steroids at physiological levels $(\mathrm{T}$, $0.002 \mathrm{mg} / \mathrm{kg} ; 11 \mathrm{kT}, 0.04 \mathrm{mg} / \mathrm{kg}$; E2, 0.02 and $0.002 \mathrm{mg} / \mathrm{kg}$; or cortisol, $0.05 \mathrm{mg} / \mathrm{kg}$; all steroids from Sigma). All doses for T, cortisol, and 11kT were the lowest one used in previous studies with type I males (RemageHealey and Bass, 2004). The two E2 doses used here were (1) the low dose used previously with type I males $(0.02 \mathrm{mg} / \mathrm{kg})$, and (2) a dose reduced by an order of magnitude $(0.002 \mathrm{mg} / \mathrm{kg})$ to further test for E2 sensitivity. Blood samples were obtained after completion of an experiment. Whole blood was separated under centrifugation, and plasma was frozen until analysis.

Receptor antagonist experiments. Previous experiments with type I males showed that the rapid actions of cortisol and $11 \mathrm{kT}$ were each separately blocked by specific steroid receptor antagonists (RemageHealey and Bass, 2004). Cyproterone acetate (CA) selectively interferes with the rapid actions of androgens but not glucocorticoids, whereas the anti-glucocorticoid mifepristone [RU486 (11 $\beta$-[(4-dimethylamino) phenyl]-17 $\beta$-hydroxy-17-(1-propynyl)estra-4,9-dien-3-one)] specifically blocks the rapid actions of glucocorticoids but not androgens. Importantly, the two forms of teleost glucocorticoid receptor are antagonized by RU486 (Bury et al., 2003), and RU486 does not compete for either the nuclear or the membrane progesterone receptor in sea trout (Thomas et al., 2007). Equally important, CA is a more effective androgen antagonist than flutamide in teleost brain (Wells and Van Der Kraak, 2000). As with type I males (Remage-Healey and Bass, 2004), type II males and females were pretreated with an intramuscular injection of either CA or RU486 $(0.25 \mathrm{mg} / \mathrm{kg} ; n=6$ for each morph for each drug) for $30 \mathrm{~min}$, and then baseline recordings were obtained as above before intramuscular injection of either (1) the steroid ( $\mathrm{T}$ at $0.002 \mathrm{mg} / \mathrm{kg}$ after $\mathrm{CA}$; cortisol at $0.05 \mathrm{mg} / \mathrm{kg}$ after RU486) or (2) nothing (a no-injection control for CA or RU486 alone). After steroid injection, a series of fictive calls were obtained as above. The most widely used estrogen receptor antagonist (ICI 182,780) was not tested here because it is not an effective blocker of rapid E2 effects in type I males (our unpublished observations).

Aromatase inhibition experiment. Results of the above experiments indicated that $\mathrm{T}$ and $\mathrm{E} 2$ exert rapid actions on fictive call duration in type II males and females. Because the enzyme aromatase is expressed in the VPG region of all adult morphs, although at much higher levels in type II males and females (Schlinger et al., 1999; Forlano and Bass, 2005), we tested whether the actions of $\mathrm{T}$ were attributable to its rapid conversion to E2 (Balthazart et al., 2003). The aromatase inhibitor fadrozole (FAD) blocks the rapid ( $5 \mathrm{~min}$ ) conversion of $\mathrm{T}$ into $\mathrm{E} 2$ by aromatase in midshipman brain homogenates (Schlinger et al., 1999). Here, type II males $(n=5)$ and females $(n=4)$ were pretreated with an intramuscular injection of FAD $(8 \mathrm{mg} / \mathrm{kg})$ for $30 \mathrm{~min}$, and then baseline measurements were obtained as above before intramuscular injection of T $(0.002 \mathrm{mg} /$ $\mathrm{kg}$ ). After T injection, a subsequent series of fictive call recordings were obtained as above. The results from the $8 \mathrm{mg} / \mathrm{kg}$ dose suggested a possible effect on the magnitude of rapid T effects in type II males (see Results), and so the dose of FAD was increased twofold (to $16 \mathrm{mg} / \mathrm{kg}$ ) in a separate group of type II males $(n=3)$, and T injections and vocal motor recordings were performed as above. To fully test the androgen and morph specificity of FAD effects, an additional series of experiments were performed with type I males $(n=3)$. Males were pretreated with intramuscular injections of FAD ( $8 \mathrm{mg} / \mathrm{kg}$; dose as above) for $30 \mathrm{~min}$, and then baseline measurements were obtained as above before intramuscular injection of $11 \mathrm{kT}(0.04 \mathrm{mg} / \mathrm{kg})$ and a subsequent series of fictive call recordings (see above).

Androgen specificity experiment. 11-Ketotestosterone is comparable with DHT in other vertebrates because both androgens are not converted to estrogens by aromatization. DHT can act as a potent agonist for the androgen receptor in teleosts (Olsson et al., 2005). To further test the specificity of the rapid 11kT (type I males) and T (type II males, females) effects on fictive calls, DHT was injected intramuscularly, and recordings were obtained similar to the steroid treatments outlined above $(n=3$ for each of the three morphs). The DHT dose used $(0.04 \mathrm{mg} / \mathrm{kg})$ was equivalent to the $11 \mathrm{kT}$ dose used in previous experiments (see above).

Hormone assays. Plasma was analyzed for steroid hormones using radioimmunoassay (RIA) and enzyme immunoassay (EIA). Cortisol and T were analyzed with RIA at Cornell's Diagnostic Laboratory, College of Veterinary Medicine. $17-\beta$-Estradiol and $11 \mathrm{kT}$ were analyzed with EIA (Cayman Chemical, Ann Arbor, MI), using techniques previously optimized for batrachoidids (Remage-Healey and Bass, 2004, 2005, 2006). All hormone doses (see above) produced levels that were within the physiological range for adult midshipman (data not shown).

Analysis. Results for hormone treatments were analyzed using Statview version 4.57 and SAS version 8 (both from SAS, Cary, NC) on withinand between-subject bases using repeated-measures ANOVA, followed by Tukey's post hoc tests for differences among sampling times. Baseline differences in vocal burst duration were analyzed on a between-morph basis using one-way ANOVA, and Bonferroni's post hoc comparisons were used to test differences in baseline durations among type I and II males and females.

\section{Results}

\section{Rapid steroid effects on vocal patterning}

In type II males and females, steroids modulated fictive call duration, and these effects varied by steroid treatment and time after injection. Repeated-measures ANOVA revealed an overall significant effect of steroid treatment $(F=14.05$; df $=3,196 ; p<$ $0.0001)$, and an interaction of steroid treatment $\times$ time after injection for fictive call duration $(F=5.82$; df $=3,196$; $p<$ $0.0001)$. There was no significant effect of steroid treatment $(p>$ 0.05 for all effects) on burst latency or discharge frequency for either type II males (latency mean \pm SEM at 30 min after injection: E2, $28.17 \pm 19.08 \mathrm{~ms}$; cortisol, $11.65 \pm 0.59 \mathrm{~ms}$; $11 \mathrm{kT}$, $18.71 \pm 0.71 \mathrm{~ms} ; \mathrm{T}, 13.78 \pm 2.68 \mathrm{~ms}$; frequency mean $\pm \mathrm{SEM}$ at 30 min after injection: E2, $116.31 \pm 6.02 \mathrm{~Hz}$; cortisol, $155.89 \pm$ $10.59 \mathrm{~Hz} ; 11 \mathrm{kT}, 108.86 \pm 3.87 \mathrm{~Hz}$; $\mathrm{T}, 114.23 \pm 7.48 \mathrm{~Hz}$ ) or females (latency mean \pm SEM at $30 \mathrm{~min}$ after injection: E2, $11.60 \pm 0.31 \mathrm{~ms}$; cortisol, $11.24 \pm 1.67 \mathrm{~ms} ; 11 \mathrm{kT}, 14.38 \pm 1.05$ $\mathrm{ms}$; $\mathrm{T}, 27.20 \pm 6.18 \mathrm{~ms}$; frequency mean \pm SEM at $30 \mathrm{~min}$ after injection: E2, $131.68 \pm 10.87 \mathrm{~Hz}$; cortisol, $175.71 \pm 16.29 \mathrm{~Hz}$; $11 \mathrm{kT}, 126.59 \pm 13.61 \mathrm{~Hz} ; \mathrm{T}, 112.05 \pm 6.03 \mathrm{~Hz}$ ).

\section{Testosterone and 11-ketotestosterone}

Rapid increases in fictive call duration occurred after $\mathrm{T}$, but not $11 \mathrm{kT}$, treatment in both type II males and females.

\section{Within-group effects}

Testosterone produced significant increases in fictive call duration over time in both type II males (Fig. $2 A)(F=5.20 ; \mathrm{df}=7,14$; $p=0.004)$ and females (Fig. $2 B)(F=2.46$; $\mathrm{df}=7,42 ; p=0.03)$. Post hoc tests revealed that T produced significant $(p<0.05)$ 


\section{A Type II males}

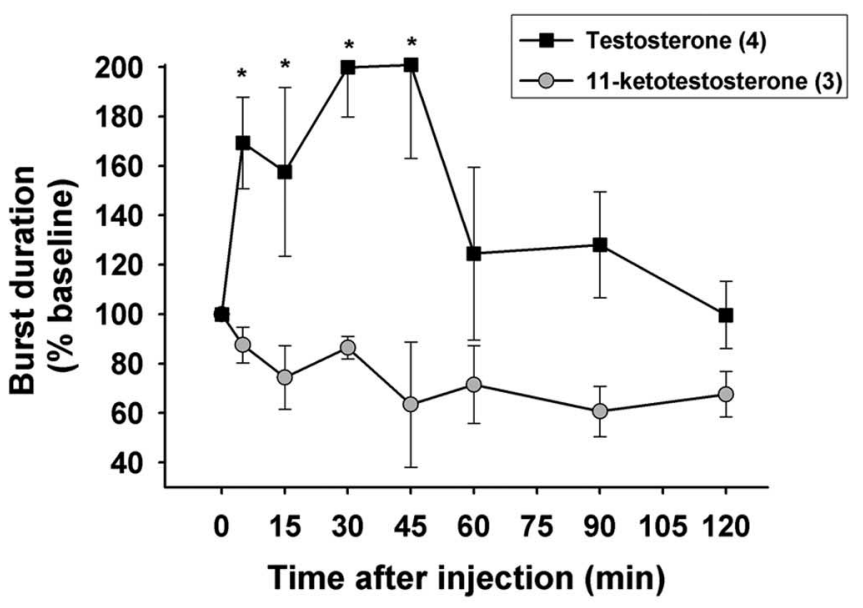

B Females

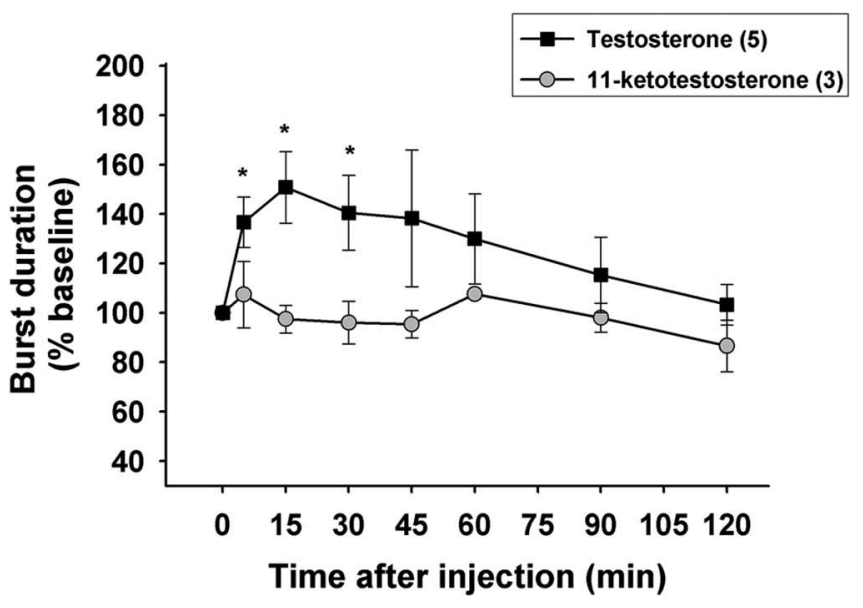

Figure 2. Rapid actions of androgens on vocal patterning in type II male $(\boldsymbol{A})$ and female $(\boldsymbol{B})$ midshipman fish. Testosterone $(0.002 \mathrm{mg} / \mathrm{kg})$ produces significant increases in vocal burst duration (expressed as percentage of a baseline value; see Materials and Methods) in both morphs, whereas 11 -ketotestosterone $(0.04 \mathrm{mg} / \mathrm{kg})$ has no effect in either morph. ${ }^{*} p<0.05$ for significant within-group differences; sample sizes are indicated in parentheses; values are mean \pm SEM. Upper bound of SEM of testosterone response in type II males does not exceed $238 \%$ (data not shown).

elevations in fictive call duration in type II males and females, respectively, at 5, 15,30, and $45 \mathrm{~min}$, and at 5, 15, and $30 \mathrm{~min}$ after injection. There were no significant changes in fictive call duration after $11 \mathrm{kT}$ injection in either type II males (Fig. $2 A)(F=$ $2.44 ; \mathrm{df}=7,14 ; p=0.07)$ or females (Fig. $2 B)(F=1.83$; $\mathrm{df}=$ $7,14 ; p=0.16)$.

Between-group effects

There were significant treatment effects on fictive calling when comparing T versus $11 \mathrm{kT}$ in type II males (Fig. $2 A$ ) (main effect: $F=10.58 ; \mathrm{df}=1,28 ; p=0.03$; interaction over time: $F=4.92$; $\mathrm{df}=7,28 ; p=0.001)$. Post hoc tests revealed significant $(p<$ 0.05 ) differences between $\mathrm{T}$ and $11 \mathrm{kT}$ at $5,15,30$, and $45 \mathrm{~min}$ in type II males. There was also a significant treatment effect when comparing T versus $11 \mathrm{kT}$ in females (Fig. $2 B$ ) (main effect: $F=$ 5.97; $\mathrm{df}=1,35 ; p=0.05$; interaction over time: $F=0.91 ; \mathrm{df}=$ $7,35 ; p=0.51)$. Post hoc tests revealed significant $(p<0.05)$

\section{A Type II males}

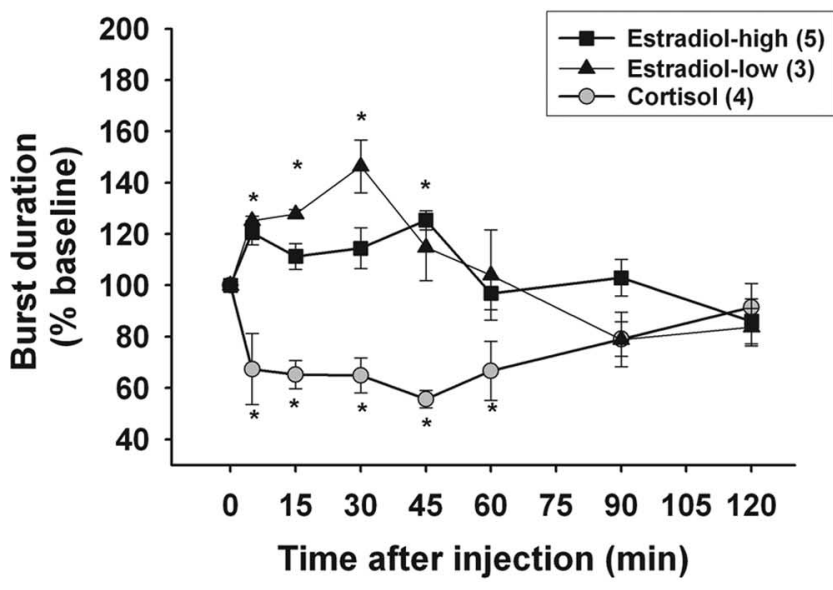

\section{B Females}

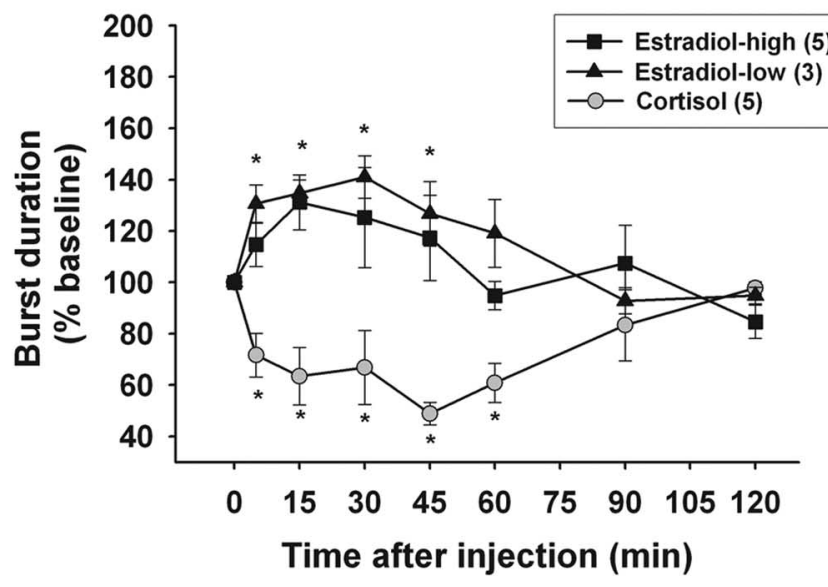

Figure 3. Rapid actions of $17-\beta$-estradiol and cortisol on vocal patterning in type Il male $(\boldsymbol{A})$ and female (B) midshipman fish. Estradiol at both low $(0.002 \mathrm{mg} / \mathrm{kg})$ and high $(0.02 \mathrm{mg} / \mathrm{kg})$ doses produces significant increases in vocal burst duration in both morphs, and cortisol $(0.05$ $\mathrm{mg} / \mathrm{kg}$ ) produces significant decreases in vocal burst duration in both morphs. ${ }^{*} p<0.05$ for significant within-group differences; sample sizes are indicated in parentheses; values are mean \pm SEM

differences between $\mathrm{T}$ and $11 \mathrm{kT}$ treatments at 5, 15, and $30 \mathrm{~min}$ in females.

\section{7- $\beta$-Estradiol}

Rapid increases in call duration occurred after E2 treatment in both type II males and females.

\section{Within-group effects}

Both low and high doses of E2 produced significant increases in fictive calling over time in both type II males (Fig. $3 A)(F=11.80$; $\mathrm{df}=7,42 ; p<0.0001)$ and females (Fig. $3 B)(F=6.48 ; \mathrm{df}=7,42$; $p<0.0001)$. For type II males, post hoc tests revealed that the 0.02 and $0.002 \mathrm{mg} / \mathrm{kg}$ doses produced significant $(p<0.05)$ elevations in fictive call duration, respectively, at 5 and $45 \mathrm{~min}$, and at 5,15 , and $30 \mathrm{~min}$ after injection. For females, post hoc tests revealed that both doses produced significant $(p<0.05)$ increases, respectively, at 5 and $15 \mathrm{~min}$, and at 5, 15, 30, and $45 \mathrm{~min}$ after injection. There were no significant interactions of dose $\times$ time for either type II males or females ( $p>0.05$ in each case), indicating that both E2 doses had broadly similar effects over time. 


\section{Cortisol}

Rapid decreases in call duration occurred after cortisol treatment in both type II males and females.

\section{Within-group effects}

Cortisol produced significant decreases in fictive calling over time in both type II males (Fig. $3 A)(F=3.55 ; \mathrm{df}=7,21 ; p=0.01)$ and females (Fig. $3 B)(F=4.73 ; \mathrm{df}=7,28 ; p=0.001)$. Post hoc tests revealed that cortisol produced significant $(p<0.05)$ suppression of fictive call duration in both type II males and females at $5,15,30,45$, and 60 min after injection.

\section{Cyproterone acetate}

The rapid actions of $\mathrm{T}$ in type II males, but not females, were inhibited by the androgen receptor antagonist CA.

Type II males, within-group effects

In the presence of $\mathrm{CA}$, $\mathrm{T}$ produced no significant changes in fictive call duration over time (Fig. $4 A)(\mathrm{T}+\mathrm{CA}, F=1.01$; $\mathrm{df}=$ $7,14 ; p=0.46)$. There was also no significant change in response to CA alone (data not shown) $(F=1.02 ; \mathrm{df}=3,6 ; p=0.49)$.

Type II males, between-group effects

Cyproterone acetate significantly altered the response to $\mathrm{T}$ (Fig. $4 A$ ). Both the main effect of treatment ( $\mathrm{T}+\mathrm{CA}$ vs $\mathrm{T}$ alone, $F=$ 6.53 ; $\mathrm{df}=1,35 ; p=0.05)$ and the interaction of treatment over time $(F=3.6 ; \mathrm{df}=7,35 ; p=0.005)$ were significantly different between $\mathrm{T}+\mathrm{CA}$ versus $\mathrm{T}$ alone. Post hoc tests revealed that CA significantly $(p<0.05)$ attenuated the rapid actions of $\mathrm{T}$ at 5,15 , 30 , and 45 min after injection.

Females, within-group effects

In the presence of $\mathrm{CA}, \mathrm{T}$ still produced significant changes in fictive call duration over time (Fig. $4 B)(\mathrm{T}+\mathrm{CA}, F=3.56$; $\mathrm{df}=$ $7,14 ; p=0.02)$. Post hoc tests revealed that $\mathrm{T}+\mathrm{CA}$ produced significant $(p<0.05)$ elevation in vocal motor activity at 5,15 , 30 , and $45 \mathrm{~min}$ after injection. There was no significant change in response to CA alone (data not shown) $(F=2.55$; $\mathrm{df}=3,6 ; p=$ $0.15)$.

Females, between-group effects

Cyproterone acetate did not significantly alter the response to $\mathrm{T}$ (Fig. $4 B$ ). Both the main effect of treatment ( $\mathrm{T}+\mathrm{CA}$ vs $\mathrm{T}$ alone, $F=0.10 ; \mathrm{df}=1,35 ; p=0.76)$ and the interaction of treatment over time $(F=1.10 ; \mathrm{df}=7,35 ; p=0.38)$ were not significantly different between $\mathrm{T}+\mathrm{CA}$ versus $\mathrm{T}$ alone.

\section{Fadrozole}

Inhibition of the conversion of $\mathrm{T}$ to $\mathrm{E} 2 \mathrm{by}$ the aromatase inhibitor FAD eliminated the rapid actions of $\mathrm{T}$ in females but not in type II males.

Type II males, within-group effects

In the presence of the aromatase inhibitor $\mathrm{FAD}, \mathrm{T}$ produced significant increases in fictive call duration over time (Fig. $4 A)(F=$ $7.24 ; \mathrm{df}=7,14 ; p=0.0009)$. Post hoc tests revealed that $\mathrm{T}+\mathrm{FAD}$ produced significant $(p<0.05)$ elevations at $5,15,30$, and 45 min after injection.

Type II males, between-group effects

Fadrozole did not significantly alter the response to T (Fig. 4A). Both the main effect of treatment $(\mathrm{T}+\mathrm{FAD}$ vs $\mathrm{T}$ alone, $F=1.06$; $\mathrm{df}=1,35 ; p=0.35)$ and the interaction of treatment over time $(F=0.99 ; \mathrm{df}=7,35 ; p=0.45)$ were not significantly different between $\mathrm{T}+\mathrm{FAD}$ low dose versus $\mathrm{T}$ alone. Despite no statistical differences, the mean responses in the $\mathrm{T}+\mathrm{FAD}$ low-dose group

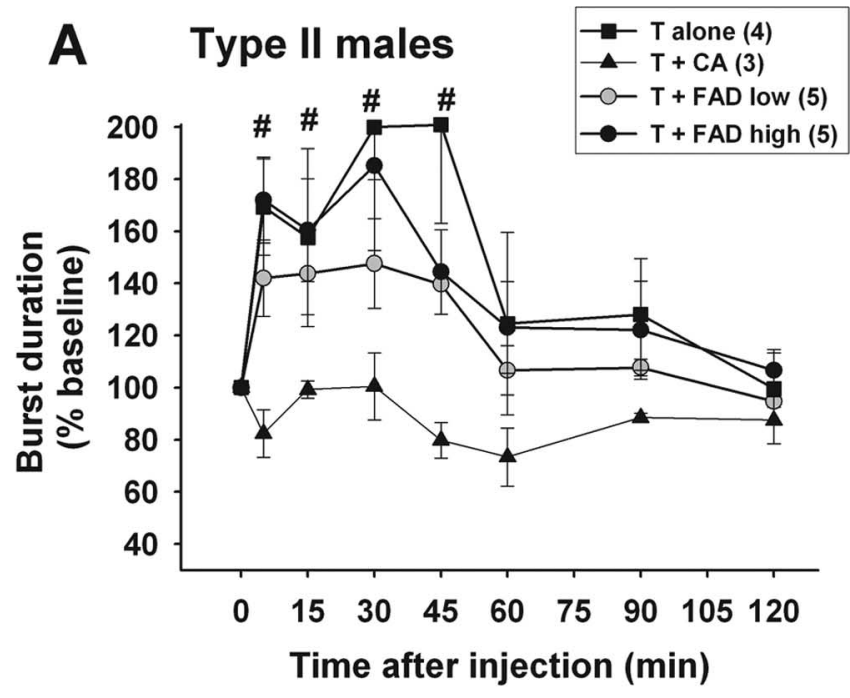

B

Females

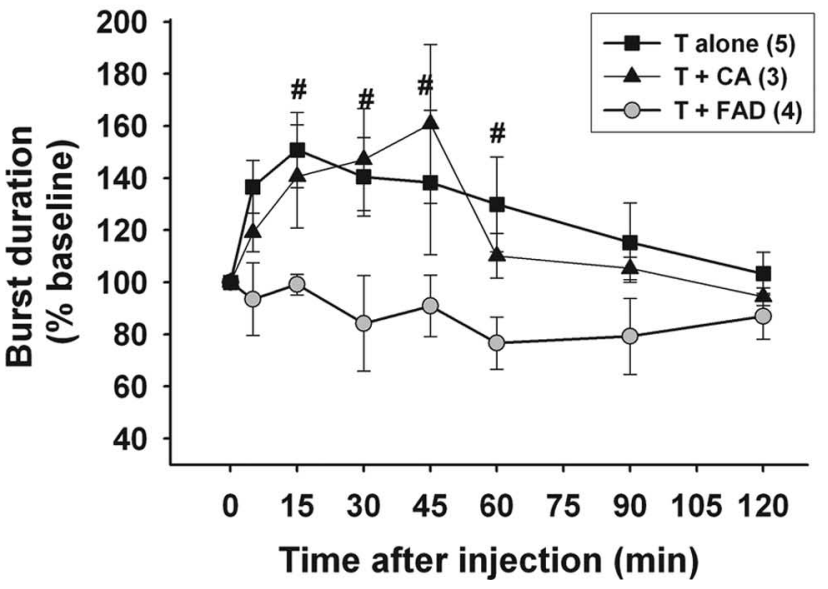

Figure 4. Rapid actions of testosterone (steroid dose as in Fig. 2) occur via distinct mechanisms in type II males $(\boldsymbol{A})$ and females $(\boldsymbol{B})$. The androgen receptor antagonist $\mathrm{CA}(0.25 \mathrm{mg} / \mathrm{kg})$ blocks the rapid actions of testosterone in type II males $(\boldsymbol{A})$, but CA has no significant effect on the response to testosterone in females $(\boldsymbol{B})$. This indicates that the actions of testosterone occur via an androgen-receptor-like mechanism in type II males but not in females. A low dose (8 $\mathrm{mg} / \mathrm{kg}$ ) of the aromatase inhibitor FAD blocks the rapid actions of testosterone in females $(\boldsymbol{B})$, but neither low nor high $(16 \mathrm{mg} / \mathrm{kg})$ doses of FAD significantly affect the response in type II males $(\boldsymbol{A})$. Thus, the actions of testosterone occur via rapid conversion to estradiol in females but not in type II males. Testosterone data shown here are the same as in Figure 2 for each morph. ${ }^{\#} p<0.05$ for significant between-group differences (T alone vs $(A+T)$ in type II males $(\boldsymbol{A})$ and for significant between-group differences (T alone vs $T+F A D)$ in females $(\boldsymbol{B})$; sample sizes are indicated in parentheses; values are mean \pm SEM. Upper bound of SEM of testosterone response in type II males does not exceed 238\% (data not shown).

were slightly lower than in the T-alone group (see Fig. 4A). To test whether there was a dosage effect, we doubled the dose of FAD (to $16 \mathrm{mg} / \mathrm{kg}$ ) for a separate set of type II males $(n=3)$. The responses were not significantly different in this $\mathrm{T}+$ FAD highdose treatment from the $\mathrm{T}+\mathrm{FAD}$ low-dose or $\mathrm{T}$-alone groups (Fig. 4A).

Females, within-group effects

In the presence of FAD, T did not produce significant changes in fictive calling over time (Fig. $4 B)(F=0.97 ; \mathrm{df}=7,21 ; p=0.47)$.

Females, between-group effects

The low dose of FAD significantly reduced the response to $\mathrm{T}$ (Fig. $4 B)$. There was a main treatment effect $(\mathrm{T}+\mathrm{FAD}$ vs $\mathrm{T}$ alone, 
$F=6.66 ; \mathrm{df}=1,42 ; p<0.05)$ but no interaction of treatment over time $(F=1.01 ; \mathrm{df}=7,42 ; p=0.43)$. Post hoc tests revealed that the response to $\mathrm{T}+\mathrm{FAD}$ was significantly reduced compared with $\mathrm{T}$ alone at 15, 30, 45, and $60 \mathrm{~min}$ after injection.

Type I males, FAD $+11 k T$ treatment

Fictive call duration in type I males rapidly increased after $11 \mathrm{kT}$ treatment, even in the presence of FAD (data not shown) $(n=3$; relative to baseline $=100 \%$ means were as follows: $5 \mathrm{~min}, 128.27$; 15 min, 149.37; 30 min, 142.02; 45 min, 150.18; 60 min, 119.47; $90 \mathrm{~min}, 129.95 ; 120 \mathrm{~min}, 119.18)$. The effect of $11 \mathrm{kT}$ treatment was highly significant in the presence of FAD $(F=24.42$; $\mathrm{df}=$ $7,14 ; p<0.005)$, supporting the steroid specificity of the effects of FAD.

\section{5- $\alpha$-Dihydrotestosterone}

There were no observed effects of DHT on fictive call duration in any adult morph (type Is, type IIs, or females). The overall effects of DHT were not significant for either the main treatment effect $(F=0.35 ; \mathrm{df}=2,42 ; p=0.72$ ) (data not shown) or for the treatment $\times$ morph interaction $(F=0.50 ; \mathrm{df}=14,42 ; p=0.92)$ (data not shown). When examined within each adult morph, DHT produced no significant effects on fictive calling in type I males ( $F=0.87$; df $=7,14 ; p=0.55$ ) (data not shown), type II males $(F=1.75, \mathrm{df}=7,14 ; p=0.18)$ (data not shown), and females $(F=1.49$; df $=7,14 ; p=0.25$ ) (data not shown). Although the rapid effects of $11 \mathrm{kT}$ alone in type I males and of $\mathrm{T}$ alone in type II males and females already show morphdependent androgen specificity, the lack of an effect of DHT (which can act as androgen agonist; see Materials and Methods) further emphasizes the distinct nature of the rapid androgen mechanisms in each morph.

\section{Mifepristone (RU486)}

The rapid, suppressive effects of cortisol were reduced in the presence of the glucocorticoid receptor antagonist RU486 in both females and type II males.

Type II males, between-group effects

The glucocorticoid receptor antagonist RU486 significantly altered the response to cortisol in type II males (Fig. $5 A$ ). Both the main effect of treatment (RU486 + cortisol vs cortisol, $F=33.29$; $\mathrm{df}=1,35 ; p=0.002)$ and the interaction of treatment over time $(F=3.36 ; \mathrm{df}=7,35 ; p=0.007)$ were significantly different between RU486 + cortisol versus cortisol-alone treatments. Post hoc tests revealed that RU486 significantly $(p<0.05)$ reduced cortisol suppression of fictive calling at $5,15,30$, and 45 min after injection. In addition, there was no significant difference between RU486 + cortisol versus RU486-alone treatments for the main effect $(F=1.85 ; \mathrm{df}=1,12 ; p=0.25)$ or the interaction effect over time $(F=2.60 ; \mathrm{df}=3,12 ; p=0.09)$.

\section{Females, between-group effects}

RU486 also significantly altered the response to cortisol in females (Fig. $5 B$ ). Both the main effect of treatment (RU486 + cortisol vs cortisol, $F=11.97$;f $=1,42 ; p=0.01)$ and the interaction of treatment over time $(F=2.86 ; \mathrm{df}=7,42 ; p=0.01)$ were significantly different between RU486 + cortisol versus cortisol-alone treatments. Post hoc tests revealed that RU486 significantly $(p<0.05)$ reduced cortisol suppression of fictive calling at 15, 45, and $60 \mathrm{~min}$ after injection. In addition, there was no significant difference between RU486 + cortisol versus RU486alone treatments for the main effect $(F=3.65$; df $=1,28$;
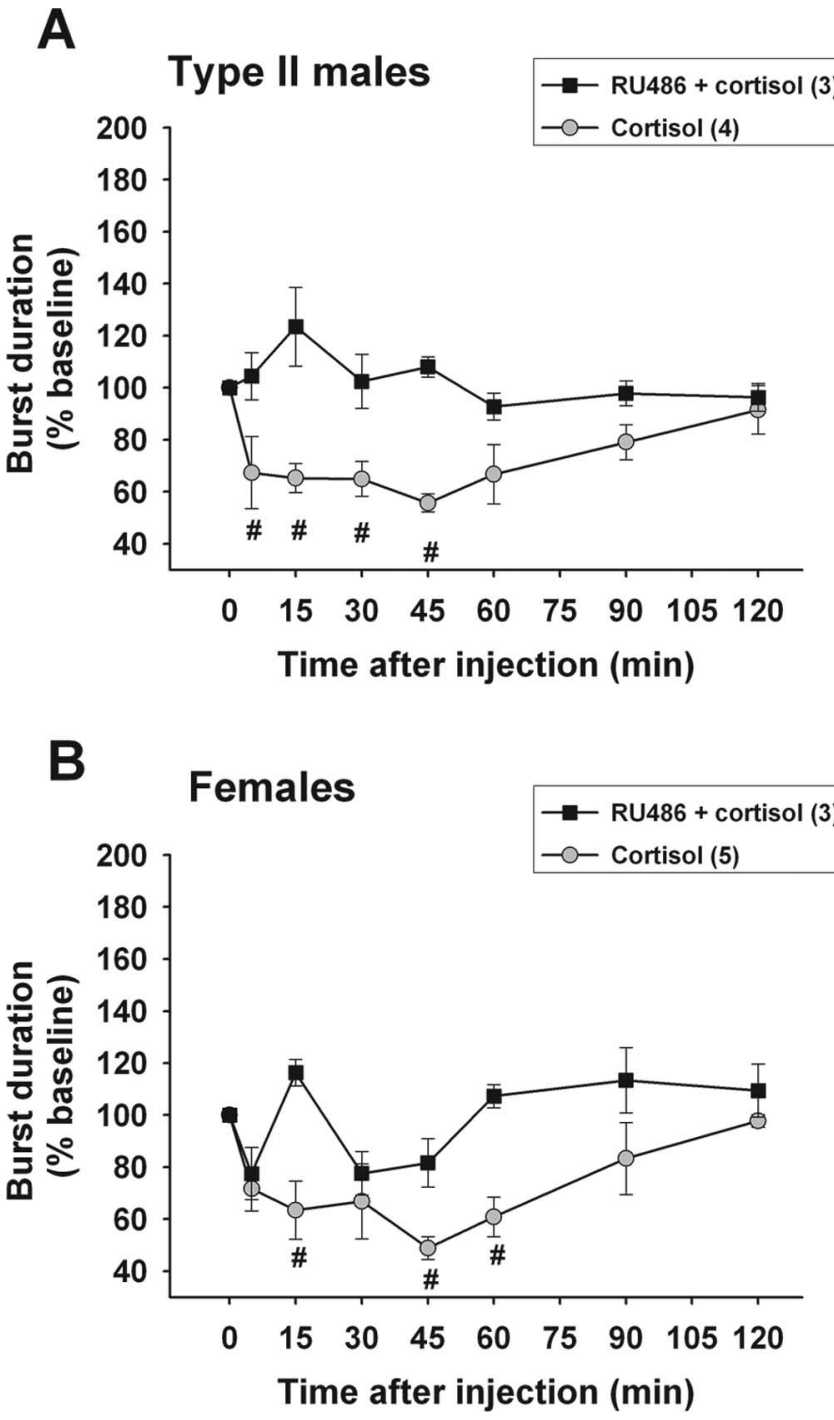

Figure 5. The glucocorticoid receptor antagonist mifepristone (RU486; $0.25 \mathrm{mg} / \mathrm{kg}$ ) blocks the rapid actions of cortisol (same dose as in Fig. 3) in type II male $(\boldsymbol{A})$ and female $(\boldsymbol{B})$ midshipman fish. ${ }^{\#} p<0.05$ for significant between-group differences (cortisol vs RU486 + cortisol) in both morphs; sample sizes are indicated in parentheses; values are mean \pm SEM.

$p=0.12)$ or the interaction effect over time $(F=0.88 ; \mathrm{df}=7,28$; $p=0.53)$.

\section{Discussion}

In this study, divergent profiles of circulating steroid hormones have direct consequences for within- and between-sex differences in the neurophysiological patterning of a social behavior. Based on these findings, we propose that (1) the organization/activation theory of steroid hormone action can include the rapid actions of steroids on central pattern generators, and (2) comparable mechanisms play a major role in the widespread distribution of divergent neuroendocrine phenotypes among vertebrates.

\section{Mechanisms of rapid steroid action}

In addition to long-term (days to weeks) effects on brain and behavior (Crews 2005), steroid hormones can act in a rapid (seconds to minutes) manner to alter neuronal excitability (Teyler et al., 1980; Rose et al., 1995; Joels, 1997; Kelly and Levin, 2001). The rapid time course (within $5 \mathrm{~min}$ ) for the steroid-specific effects observed here are consistent with a nontranscriptional mode of 
action, via extranuclear (membrane) actions, and with the ligand specificity of extranuclear steroid binding sites in the brain (Towle and Sze, 1983; Grazzini et al., 1998) and periphery (Loomis and Thomas, 2000). The present results suggest that extranuclear actions on neurons can be inhibited by conventional nuclear steroid receptor antagonists, indicating a similarity of ligand-binding domains between nuclear and extranuclear sites of steroid action (for estrogens, see Razandi et al., 1999). Notably, the specificity of rapid androgen actions (11kT vs T vs DHT) implies that neuronal androgen binding sites are markedly "tuned" in midshipman, consistent with the specificity of both nuclear and membrane androgen receptors observed in other teleosts (Olsson et al., 2005; Thomas et al., 2006).

Intact and surgical isolation experiments in type I male midshipman localize the rapid actions of steroids to the VPG region (Remage-Healey and Bass, 2004), and neuroanatomical evidence demonstrates that estrogen and androgen receptors and the enzyme aromatase are expressed within the VPG (Fig. 1) (Forlano and Bass, 2005; Forlano et al., 2005a,b). Therefore, the VPG is a candidate locus for the rapid events observed here via nuclear and/or extranuclear steroid receptors (glucocorticoid receptor expression is under study).

\section{Morph-specific patterns of rapid steroid sensitivity}

The diversity of responses to androgens observed here reflects the predominant circulating androgen in each adult morph (11kT in type I males vs T in type II males and females). Fictive calling in type II males and females is rapidly modulated by T but not $11 \mathrm{kT}$, whereas a previous study of type I males reported the inverse pattern (Remage-Healey and Bass, 2004). A comparable result occurs in rat hippocampal slices, in which sex differences in the rapid actions of steroids on neuronal excitability are related to the relative levels of circulating $\mathrm{T}$ and E2 (Smith et al., 2002). Together, these data indicate that one functional consequence of differences in adult steroid levels is the steroid-specific, rapid modulation of neural function and behavior (for a supporting microdialysis study, see Castner et al., 1993).

The rapid actions of E2 on fictive calling are similar in direction (increase), time course, and magnitude among all three adult morphs (Remage-Healey and Bass, 2004; this report), consistent with evidence for rich expression of aromatase, the enzyme that converts T to E2, in the VPG of all morphs (Schlinger et al., 1999; Forlano and Bass, 2005). Rapid estrogen regulation of neuronal activity is widespread in vertebrates (for review, see Joels, 1997; McEwen, 2002), consistent with evidence that the ancestral steroid hormone receptor was an estrogen-like receptor (Thornton et al., 2003).

In females alone, the rapid actions of $\mathrm{T}$ are completely eliminated by aromatase inhibition but not androgen receptor blockade, suggesting that $\mathrm{T}$ effects are entirely dependent on rapid $\mathrm{T}$ conversion to E2. This neuromodulatory pattern is reversed in type II males. Therefore, whereas some central aromatization of androgens and/or neurosteroid precursors into E2 may provide a local E2 source for rapid neural effects in type II males, aromatization does not account for the predominant effects of $\mathrm{T}$ (for similar results in hippocampal slices, see Teyler et al., 1980). Rapid changes in the androgen/estrogen ratio may yet modulate call patterning in midshipman, as suggested for reproductive behaviors in other teleosts (Black et al., 2005) and birds (Cornil et al., 2006).

The influence of cortisol on fictive calling is distinct: it rapidly suppresses fictive call duration in type II males and females (this report) but increases fictive call duration in type I males
Table 1. The rapid effects of steroid hormones on fictive call duration in plainfin midshipman are convergent between type II males and females but divergent from type I males

\begin{tabular}{lllll}
\hline Sex/steroid & $11 \mathrm{kT}$ & Testosterone & Estradiol & Cortisol \\
\hline Type I male & $\uparrow$ & $\leftrightarrow$ & $\uparrow$ & $\uparrow$ \\
Type II male & $\leftrightarrow$ & $\uparrow$ & $\uparrow$ & $\downarrow$ \\
Female & $\leftrightarrow$ & $\uparrow$ & $\uparrow$ & $\downarrow$
\end{tabular}

Upward arrows indicate significant rapid elevation, downward arrows indicate significant, rapid suppression, and even arrows indicate no significant changes after steroid injection. Data for type I males are adapted from RemageHealey and Bass (2004).

(Remage-Healey and Bass, 2004). This suggests that cortisol acts via a similar receptor mechanism (sensitive to RU486) in all three morphs but that downstream effectors such as second messengers (Abraham and Herbison, 2005) or coactivators (Balthazart et al., 2003) within vocal neurons are divergent. These results suggest that acute stress is associated with increased versus decreased vocal production in, respectively, type I males versus type II males and females. Consistent with this, type I males display agonistic grunting and/or biting when other type I or II males approach their nest, whereas type II males and females are usually silent at such times (Brantley and Bass, 1994). The prediction for type I males is consistent with elevated cortisol levels in calling, territorial males of the closely related toadfish Opsanus beta, which have been proposed to support the energetic demands of extensive calling through energy mobilization (Remage-Healey and Bass, 2005). The prediction for type II males and females is consistent with studies of (1) elevated glucocorticoids in type II-like male sunfish (Knapp, 2003) and in nondominant individuals in other teleosts (Johnsson et al., 2006), and (2) glucocorticoid suppression of reproductive vocal behaviors in tetrapods (Wingfield and Silverin, 1986; Marler and Ryan, 1996; Leary et al., 2006).

Field studies are just beginning to reveal the relationship between steroids and vocalizations in teleosts. Territorial male toadfishes show elevated plasma $11 \mathrm{kT}$ and cortisol when transitioning from non-calling to calling states (Knapp et al., 2001; Remage-Healey and Bass, 2005). 11-Ketotestosterone treatment elevates fictive call duration into the range of natural advertisement hums in type I male midshipman (Remage-Healey and Bass, 2004), whereas the current results show that E2 and T elevate fictive call duration into the range of natural grunts produced by type II males and females during the breeding season (>50 ms) (Brantley and Bass, 1994) (A.H.B., unpublished observations). We therefore predict that circulating $\mathrm{T}$ and/or E2 levels undergo rapid plasma and/or central fluctuations during periods of agonistic/reproductive grunting in type II males and females.

Together, these results are significant in two primary ways. First, type II males and females achieve similar neuromodulation by steroids via a mixture of separate $(\mathrm{T})$ and convergent (E2, cortisol) mechanisms. Rapid $\mathrm{T}$ action is mainly achieved via $\mathrm{T}$ acting as an androgen in type II males and as an estrogen, via aromatization, in females. Thus, the patterns of steroid neuromodulation of the VPG are morph specific and reflect behavioral, and not gonadal, phenotype (Table 1). Second, however, both type I and II males exhibit neuromodulation by androgens (11kT and $\mathrm{T}$, respectively), which is dependent on androgen receptors and not on aromatization (Table 2). Type II males, therefore, represent a blend of female-like vocal characters (neuronal morphology and behavior) and rapid androgen mechanisms that reflect a male gonadal phenotype. 
Table 2. The mechanisms of rapid steroid action are dependent on gonadal phenotype

\begin{tabular}{llll}
\hline & $\begin{array}{l}\text { Androgen } \\
\text { action blocked }\end{array}$ & $\begin{array}{l}\text { Androgen } \\
\text { action blocked } \\
\text { by FAD? }\end{array}$ & $\begin{array}{l}\text { Cortisol action blocked } \\
\text { by RU486? }\end{array}$ \\
\hline Type I male & Yes & No & Yes \\
Type II male & Yes & No & Yes \\
Female & No & Yes & Yes \\
\hline
\end{tabular}

The androgen receptor antagonist CA eliminates the rapid effects of androgens in type I and type II males, but not females, whereas the aromatase inhibitor FAD blocks the rapid effects of androgens in females but not type I and type II males. The glucocorticoid receptor antagonist RU486 eliminates the rapid effects of cortisol in all three adult midshipman morphs. Data for type I males for CA and RU486 are adapted from Remage-Healey and Bass (2004).

\section{Evolution of alternative neuroendocrine phenotypes}

Type II males and females: ancestral neuroendocrine phenotype We propose that type II males and females express a suite of ancestral, "vertebrate-typical" neuroendocrine mechanisms. In type II males and females, reproduction-related motor output is augmented by both E2- and T-dependent mechanisms but suppressed by the glucocorticoid cortisol. Such roles for these steroids are present throughout vertebrates (Moore and Miller, 1984; Sapolsky, 1993; Meddle et al., 2002; White et al., 2002; Crews, 2005; Moore et al., 2005), suggesting an ancestral group of neuroendocrine mechanisms.

\section{Type I territorial males: novel neuroendocrine phenotype}

In contrast, we propose that type I males express a suite of novel neuroendocrine mechanisms. First, type I males are the only adult morph in which the teleost-specific androgen $11 \mathrm{kT}$ rapidly affects neural patterning. Second, unlike most vertebrates (see above), in type I males, cortisol augments, rather than suppresses, reproduction-related vocal output (Remage-Healey and Bass, 2004).

The novel phenotype adopted by type I males is closely linked to circulating $11 \mathrm{kT}$, an innovation apparently specific to actinopterygian fishes (Borg, 1994), among which teleosts predominate (Nelson, 1994). Importantly, there is no sex difference in $11 \mathrm{kT}$ levels in either the basal teleost genus Anguilla (Lokman et al., 2002) or the chondrostean Acipenser baeri (Cuisset et al., 1995), a more basal actinopterygian (Nelson, 1994). Thus, the generally higher plasma levels of $11 \mathrm{kT}$ in male teleosts represents a more derived character within this lineage and is also characteristic of the territorial/parental morph in species with ARTs (Brantley et al., 1993; Oliveira, 2004). 11-Ketotestosterone could therefore be a "basal" innovation that was permissive for the evolution of teleost ARTs. The principle role of 11ketotestosterone in regulating the expression of type I male-like secondary sex traits (Brantley et al., 1993; Borg, 1994) and exclusive male parental care (Magee et al., 2006; Rodgers et al., 2006) suggests a key innovation in the widespread evolution of ARTs among teleosts (Mank and Avise, 2006). Recent discoveries of a teleost androgen receptor specifically activated by $11 \mathrm{kT}$ (Olsson et al., 2005) and an 11kT-responsive membrane androgen receptor (Thomas et al., 2006) may provide clues about the molecular origins and refinement of $11 \mathrm{kT}$-dependent mechanisms.

\section{Concluding comments}

Each adult midshipman morph is characterized by a suite of traits (Bass, 1996), which can apparently evolve independently (Goodson and Bass, 2000; Lee and Bass, 2005). Accordingly, individual ART traits can be shaped by activational and/or organizational steroid mechanisms to provide a rich array of phenotypic variation. Consistent with this conceptual framework, the plasticity of rapid neuroendocrine mechanisms shown here appears to reflect the influences of developmental organization (male vs female gonadal phenotype) on patterns of rapid neuromodulation during adulthood (morph-specific phenotype). Therefore, we propose that the fundamental organization/activation theory of steroid hormone action, [that steroids bind to nuclear receptors during development and adulthood to shape neural/behavioral phenotypes (Phoenix et al., 1959; Arnold and Breedlove, 1985; Emerson, 2000)], can be expanded to include the rapid actions of steroid hormones on the neurophysiological mechanisms of adult behavior. Comparable steroid mechanisms may explain the widespread distribution of divergent neural/behavioral patterns among teleosts with ARTs, as well as the many examples of intrasexual divergence in behavioral phenotypes among tetrapods (Rhen and Crews, 2002; Roselli et al., 2004), including humans and other primates (Gladue et al., 1984; Maggioncalda et al., 2002; Morris et al., 2004).

\section{References}

Abraham IM, Herbison AE (2005) Major sex differences in non-genomic estrogen actions on intracellular signaling in mouse brain in vivo. Neuroscience 131:945-951.

Arnold AP, Breedlove SM (1985) Organizational and activational effects of sex steroids on brain and behavior: a reanalysis. Horm Behav 19:469-498.

Balthazart J, Baillien M, Charlier TD, Cornil CA, Ball GF (2003) Multiple mechanisms control brain aromatase activity at the genomic and nongenomic level. J Steroid Biochem Mol Biol 86:367-379.

Bass AH (1996) Shaping brain sexuality. Am Sci 84:352-363.

Bass AH, Baker R (1990) Sexual dimorphisms in the vocal control-system of a teleost fish: morphology of physiologically identified neurons. J Neurobiol 21:1155-1168.

Black MP, Balthazart J, Baillien M, Grober MS (2005) Socially induced and rapid increases in aggression are inversely related to brain aromatase activity in a sex-changing fish, Lythrypnus dalli. Proc Roy Soc Lond B Biol Sci 272:2337-2344.

Borg B (1994) Androgens in teleost fishes. Comp Biochem Physiol C Pharm Toxicol Endocrinol 109:219-245.

Brantley RK, Bass AH (1994) Alternative male spawning tactics and acoustic-signals in the plainfin midshipman fish Porichthys-notatus Girard (Teleostei, Batrachoididae). Ethology 96:213-232.

Brantley RK, Wingfield JC, Bass AH (1993) Sex steroid-levels in Porichthysnotatus, a fish with alternative reproductive tactics, and a review of the hormonal bases for male dimorphism among teleost fishes. Horm Behav 27:332-347.

Bury NR, Sturm A, Le Rouzic P, Lethimonier C, Ducouret B, Guiguen Y, Robinson-Rechavi M, Laudet V, Rafestin-Oblin ME, Prunet P (2003) Evidence for two distinct functional glucocorticoid receptors in teleost fish. J Mol Endocrinol 31:141-156.

Castner SA, Xiao L, Becker JB (1993) Sex-differences in striatal dopamine: in vivo microdialysis and behavioral studies. Brain Res 610:127-134.

Cornil CA, Taziaux M, Baillien M, Ball GF, Balthazart J (2006) Rapid effects of aromatase inhibition on male reproductive behaviors in Japanese quail. Horm Behav 49:45-67.

Crews D (2005) Evolution of neuroendocrine mechanisms that regulate sexual behavior. Trends Endocrinol Metab 16:354-361.

Cuisset B, Fostier A, Williot P, Bennetaupelissero C, Lemenn F (1995) Occurrence and in-vitro biosynthesis of 11-ketotestosterone in siberian sturgeon, Acipenser baeri Brandt maturing females. Fish Physiol Biochem 14:313-322.

de Vries GJ, McCarthy MM, eds (2006) Special issue: translational topics in behavioral neuroendocrinology. Horm Behav 50:503-664.

Emerson SB (2000) Vertebrate secondary sexual characteristics: physiological mechanisms and evolutionary patterns. Am Nat 156:84-91.

Forlano PM, Bass AH (2005) Seasonal plasticity of brain aromatase mRNA expression in glia: divergence across sex and vocal phenotypes. J Neurobiol 65:37-49.

Forlano PM, Deitcher DL, Bass ARH (2005a) Distribution of estrogen receptor alpha mRNA in the brain and inner ear of a vocal fish with comparisons to sites of aromatase expression. J Comp Neurol 483:91-113.

Forlano PM, Marchaterre MA, Deitcher DL, Bass AH (2005b) Distribution 
of androgen receptor mRNA in vocal and nonvocal circuitry of a teleost fish. Soc Neurosci Abstr 31:1001.6.

Gladue BA, Green R, Hellman RE (1984) Neuroendocrine response to estrogen and sexual orientation. Science 225:1496-1499.

Goodson JL, Bass AH (2000) Forebrain peptides modulate sexually polymorphic vocal circuitry. Nature 403:769-772.

Goodson JL, Bass AH (2002) Vocal-acoustic circuitry and descending vocal pathways in teleost fish: convergence with terrestrial vertebrates reveals conserved traits. J Comp Neurol 448:298-322.

Grazzini E, Guillon G, Mouillac B, Zingg HH (1998) Inhibition of oxytocin receptor function by direct binding of progesterone. Nature 392:509-512.

Joels M (1997) Steroid hormones and excitability in the mammalian brain. Front Neuroendocrinol 18:2-48.

Johnsson JI, Winberg S, Sloman KA (2006) Social interactions. In: Behaviour and physiology of fish, Vol 24, Fish physiology (Sloman KA, Wilson RW, Balshine S, eds), pp 151-196. New York: Elsevier Academic.

Kelly MJ, Levin ER (2001) Rapid actions of plasma membrane estrogen receptors. Trends Endocrinol Metab 12:152-156.

Kittelberger JM, Land BR, Bass AH (2006) The midbrain periaqueductal gray and vocal patterning in a teleost fish. J Neurophysiol 96:71-85.

Knapp R (2003) Endocrine mediation of vertebrate male alternative reproductive tactics: the next generation of studies. Integr Comp Biol 43:658-668.

Knapp R, Wingfield JC, Bass AH (1999) Steroid hormones and paternal care in the plainfin midshipman fish (Porichthys notatus). Horm Behav 35:81-89.

Knapp R, Marchaterre MA, Bass AH (2001) Relationship between courtship behavior and steroid hormone levels in parental male plainfin midshipman fish. Horm Behav 39:335.

Leary CJ, Garcia AM, Knapp R (2006) Elevated corticosterone levels elicit non-calling mating tactics in male toads independently of changes in circulating androgens. Horm Behav 49:425-432.

Lee JSF, Bass AH (2005) Differential effects of 11-ketotestosterone on dimorphic traits in a teleost with alternative male reproductive morphs. Horm Behav 47:523-531.

Lokman PM, Harris B, Kusakabe M, Kime DE, Schulz RW, Adachi S, Young G (2002) 11-oxygenated androgens in female teleosts: prevalence, abundance, and life history implications. Gen Comp Endocrinol 129:1-12.

Loomis AK, Thomas P (2000) Effects of estrogens and xenoestrogens on androgen production by Atlantic croaker testes in vitro: Evidence for a nongenomic action mediated by an estrogen membrane receptor. Biol Reprod 62:995-1004.

Magee SE, Neff BD, Knapp R (2006) Plasma levels of androgens and cortisol in relation to breeding behavior in parental male bluegill sunfish, Lepomis macrochirus. Horm Behav 49:598-609.

Maggioncalda AN, Czekala NM, Sapolsky RM (2002) Male orangutan subadulthood: a new twist on the relationship between chronic stress and developmental arrest. Am J Phys Anthropol 118:25-32.

Mank JE, Avise JC (2006) Comparative phylogenetic analysis of male alternative reproductive tactics in ray-finned fishes. Evolution 60:1311-1316.

Marler CA, Ryan MJ (1996) Energetic constraints and steroid hormone correlates of male calling behaviour in the tungara frog. J Zool 240:397-409.

McEwen B (2002) Estrogen actions throughout the brain. Rec Prog Horm Res 57:357-384.

Meddle SL, Romero LM, Astheimer LB, Buttemer WA, Moore IT, Wingfield JC (2002) Steroid hormone interrelationships with territorial aggression in an arctic-breeding songbird, Gambel's white-crowned sparrow, Zonotrichia leucophrys gambelii. Horm Behav 42:212-221.

Moore FL, Miller LJ (1984) Stress-induced inhibition of sexual-behavior: corticosterone inhibits courtship behaviors of a male amphibian (Taricha-granulosa). Horm Behav 18:400-410.

Moore FL, Boyd SK, Kelley DB (2005) Historical perspective: hormonal regulation of behaviors in amphibians. Horm Behav 48:373-383.

Morris JA, Jordan CL, Breedlove SM (2004) Sexual differentiation of the vertebrate nervous system. Nat Neurosci 7:1034-1039.

Nelson JS (1994) Fishes of the world. New York: Wiley.

Oliveira RF (2004) Social modulation of androgens in vertebrates: mechanisms and function. Adv Stud Behav 34:165-239.
Oliveira RF, Ros AFH, Goncalves DM (2005) Intra-sexual variation in male reproduction in teleost fish: a comparative approach. Horm Behav 48:430-439.

Olsson PE, Berg AH, von Hofsten J, Grahn B, Hellqvist A, Larsson A, Karlsson J, Modig C, Borg B, Thomas P (2005) Molecular cloning and characterization of a nuclear androgen receptor activated by 11-ketotestosterone. Reprod Biol Endocrinol 3:37-54.

Phoenix CH, Goy RW, Gerall AA, Young WC (1959) Organizing action of prenatally administered testosterone propionate on the tissues mediating mating behavior in the female guinea pig. Endocrinology 65:369-382.

Razandi M, Pedram A, Greene GL, Levin ER (1999) Cell membrane and nuclear estrogen receptors (ERs) originate from a single transcript: studies of ER alpha and ER beta expressed in Chinese hamster ovary cells. Mol Endocrinol 13:307-319.

Remage-Healey L, Bass AH (2004) Rapid, hierarchical modulation of vocal patterning by steroid hormones. J Neurosci 24:5892-5900.

Remage-Healey L, Bass AH (2005) Rapid elevations in both steroid hormones and vocal signaling during playback challenge: a field experiment in Gulf toadfish. Horm Behav 47:297-305.

Remage-Healey L, Bass AH (2006) From social behavior to neural circuitry: steroid hormones rapidly modulate advertisement calling via a vocal pattern generator. Horm Behav 50:432-441.

Rhen T, Crews D (2002) Variation in reproductive behaviour within a sex: neural systems and endocrine activation. J Neuroendocrinol 14:517-531.

Rodgers EW, Earley RL, Grober MS (2006) Elevated 11-ketotestosterone during paternal behavior in the bluebanded goby (Lythrypnus dalli). Horm Behav 49:610-614.

Rose JD, Kinnaird JR, Moore FL (1995) Neurophysiological effects of vasotocin and corticosterone on medullary neurons: implications for hormonal-control of amphibian courtship behavior. Neuroendocrinology 62:406-417.

Roselli CR, Larkin K, Schrunk JM, Stormshak F (2004) Sexual partner preference, hypothalamic morphology and aromatase in rams. Physiol Behav 83:233-245.

Sapolsky RM (1993) Endocrinology alfresco: psychoendocrine studies of wild baboons. Rec Prog Horm Res 48:437-468.

Schlinger BA, Creco C, Bass AH (1999) Aromatase activity in the hindbrain vocal control region of a teleost fish: divergence among males with alternative reproductive tactics. Proc R Soc Lond B Biol Sci 266:131-136.

Sisneros JA, Forlano PM, Knapp R, Bass AH (2004) Seasonal variation of steroid hormone levels in an intertidal-nesting fish, the vocal plainfin midshipman. Gen Comp Endocrinol 136:101-116.

Smith MD, Jones LS, Wilson MA (2002) Sex differences in hippocampal slice excitability: role of testosterone. Neuroscience 109:517-530.

Teyler TJ, Vardaris RM, Lewis D, Rawitch AB (1980) Gonadal-steroids: effects on excitability of hippocampal pyramidal cells. Science 209:1017-1019.

Thomas P, Dressing G, Pang Y, Berg H, Tubbs C, Benninghoff A, Doughty K (2006) Progestin, estrogen and androgen G-protein coupled receptors in fish gonads. Steroids 71:310-316.

Thomas P, Pang Y, Dong J, Groenen P, Kelder J, de Vlieg J, Zhu Y, Tubbs C (2007) Steroid and G protein binding characteristics of the seatrout and human progestin membrane receptor alpha subtypes and their evolutionary origins. Endocrinology, in press.

Thornton JW, Need E, Crews D (2003) Resurrecting the ancestral steroid receptor: ancient origin of estrogen signaling. Science 301:1714-1717.

Towle AC, Sze PY (1983) Steroid binding to synaptic plasma-membrane: differential binding of glucocorticoids and gonadal-steroids. J Steroid Biochem Mol Biol 18:135-143.

Wells K, Van Der Kraak G (2000) Differential binding of endogenous steroids and chemicals to androgen receptors in rainbow trout and goldfish. Env Toxicol Chem 19:2059-2065.

White SA, Nguyen T, Fernald RD (2002) Social regulation of gonadotropinreleasing hormone. J Exp Biol 205:2567-2581.

Wingfield JC, Silverin B (1986) Effects of corticosterone on territorial behavior of free-living male song sparrows Melospiza-melodia. Horm Behav 20:405-417. 